\title{
Comparison of Sampling Methods for Estimating Seed Bank and Weed Population Densities during the Growing Season
}

\author{
Masoomeh Gholami Golafshan ${ }^{1} \&$ Esmaeil Yasari ${ }^{2}$ \\ ${ }^{1}$ Department of Agriculture, Payame Noor University, Iran \\ ${ }^{2}$ Assisstant Prof. Department of Agriculture, Payame Noor University, Iran \\ Correspondence: Esmaeil Yasari, Assisstant Prof. Department of Agriculture, Payame Noor University, Iran. \\ E-mail: e_yassari@yahoo.com
}

Received: April 10, 2012 Accepted: April 25, 2012 Online Published: July 26, 2012

doi:10.5539/jas.v4n9p39 URL: http://dx.doi.org/10.5539/jas.v4n9p39

\begin{abstract}
In order to compare sampling methods for estimating the populations of the seed bank and the populations of weed seedlings during the growing season in the field, an experiment was conducted in the research field of the Agriculture college of Karaj in the cropping year of 2007. In this experiment, sampling of the seed bank was carried out first at the start of the growing season. Then, during the growing season, the weed populations were sampled in 96 points using the networking method, and their means were considered as the base and the real means of the populations of the weeds. Next, to compare other methods with the networking method, sampling was carried out using the systematic, the diagonal, and the random methods, and then the variance of error of each method was calculated and compared with that of the networking method in the format of factorial using a completely randomized design. The first factor studied, the species of weeds, included the three species of grasses, Amaranthus, and Portulaca. The zigzag, the diagonal, and the random sampling methods constituted the second factor. Results relating to the seed bank and those concerning the populations of the weeds were different from each other. The results obtained showed that the suitable method for each species differed according to the different distribution patterns of the weed species in the field. In the seed bank, there were no significant differences among sampling methods for any of the species, but the random method for grasses and Portulaca showed the least error in predicting weed populations. Altogether, among the sampling methods used for Amaranthus, there were no differences in accuracy. Concerning the populations of weed seedlings, the random method for broadleaf weeds (Amaranthus and Portulaca), and the zigzag method for grasses, were the best. As for the seed bank, the variance of error of all the methods decreased with an increase in the number of samples taken; and when more than 15 samples were taken, this trend of decrease in the variance of error stabilized and no more reduction in error was observed. Regarding the populations of the weeds, no trend was found between the number of samples taken and the variance of error.
\end{abstract}

Keywords: sampling method, systematic method, weed population estimate

\section{Introduction}

The seed bank is like a tablet preserving in itself the plant history of the region; and to a large extent determines the future plant populations in the region (Ball, 1992). Although it seems impossible to obtain complete information on all aspects of the seed bank and to accurately predict the weed flora by using this information, yet the composition and the densities of the species in the seed bank provides valuable information for the management of weeds. Ecological knowledge creates a perspective which makes it possible to better concentrate on a range of management operations (Forcella et al., 1996).

Accurate methods based on thresholds of damage and on models of weed population dynamics were developed to help farm managers to control weeds in the short- and in the long run. In these methods, the weed populations observed in the field are compared with the thresholds of weed densities to figure out whether it is necessary to control and fight the weeds. These threshold densities of weeds affect the yield of the crop (reduce yield) and also entail great expenses in controlling and fighting weeds (Zadokas, 1985). If the population of the weeds is greater than the threshold level, herbicides are used; but if it is less than the threshold level, control methods are not employed. In the methods of weed population dynamics, features of the weed population, such as the density of the seedlings, the abundance of seeds produced, and estimates of the number of seeds in the field, are assessed and 
then are used for simulating the long term growth model of the weeds (Colbach \& Debaeke, 1998). Such methods require accurate evaluation of the densities of the weeds in order to allow correct decision making. Of course, in some cases, the extent of the error observed in the long term plans of weed control management is permissible (Wallinga et al., 1999).

Most methods used for estimating and evaluating the densities of weed populations are based on maps obtained from data gathered in the field. In sampling conducted with the purpose of assessing the densities of weed populations, the purposes of the project consist of selecting a certain number of samples, choosing a quadrat with known and suitable dimensions, deciding on the sampling points, networking the field, counting the number of the seedlings of each weed species in the quadrat, and calculating the mean density of each weed species in the quadrat. This is a suitable method if we do not have other information for estimating the densities of the weed species in the field. Although weed distribution in the field is patchy, and weeds are not randomly distributed in the field (Marshall, 1988; Thornton et al., 1990; Wiles et al., 1992; Johnson et al., 1996), these patches reduce the accuracy of methods based on the density of weeds (Auld \& Tisdell, 1987; Dent et al., 1989; Brain \& Cousens, 1990).

Predicting the mean density of a certain amount of weeds for the purpose of evaluating the population of the weeds indicated that the samples taken close together were less diverse than those taken farther apart (Legendre \& Fortin, 1989; Gold et al., 1996).

Samples taken for the purpose of finding the spatial distribution of weed populations may increase the efficiency of sampling (Cardina et al., 1997). For example, in sampling, the field may be divided into separate parts and the mean density for each part is separately calculated. Such methods may decrease diversity in the estimation and in the evaluation of the densities of the weeds, compared with the evaluation of the entire field.

In recent years, a number of research projects have been carried out to optimize sampling weeds so that sufficient and useful information on the densities of weed populations, on weed distribution, and on correct evaluation can be obtained without spending too much time or money. In most of these research activities, finding desirable and effective methods has been possible by employing useful information available from before. Conn et al., (1982) used systematic, serial, random, and stratified methods of sampling to estimate weed populations in the field.

The purposes of this study were to compare sampling methods on the basis of correctness and accuracy of the estimates, to evaluate the means of the densities of weed seedlings during the growing season, and also to employ the best sampling method for making decisions concerning weed control management. The various sampling methods for estimating weed densities in fields devoted to crop production are not applied methods: they must be tested to choose the method which is most accurate in estimating weed densities.

\section{Materials and Method}

This experiment was conducted in the factorial format using a completely randomized design in the research field of the agronomy department of the Islamic Azad University of Karaj in 2007. This research field has a latitude of $35^{\circ} 45^{\prime}$ North, a longitude of $51^{\circ} 6^{\prime}$ East, and an altitude of $1313 \mathrm{~m}$ above sea level. Climate-wise, Karaj is classified as a semi-arid region. The soil in the field was tested and it was found to be loamy sand with a pH of about 8 , an EC of 1.4, and an acidity equivalent to 7.6. The dimensions of the field were 20 by $60 \mathrm{~m}$ and corn was planted in it.

Land preparation included plowing with a reversible plow, two disking operations in perpendicular directions, and the leveling of the land. $250 \mathrm{Kg}$.h of ammonium phosphate was applied to the field as the base fertilizer. To study the seed bank and the weed populations, after final land preparation operations, the field was divided and roped into 4 by 4 meter networks. The intersections of the networks were marked, staked, and used as the sampling points all through the growing season. The seeds were disinfected with a fungicide and planted by hand at a depth of 3 centimeters on May $14^{\text {th }}$, 2007. In each hill, 2-3 seeds were placed and, at the four - leaf stage, thinning was performed to have 80000 plants per hectare.

\subsection{Sampling the Seed Bank}

Soil sampling was conducted using an auger with a $5 \mathrm{~cm}$ diameter. The quadrat (which had an area of $0.25 \mathrm{~m}^{2}$ ) was placed in such a way that the staked points lay at its center. From the area inside the quadrat, 5 soil samples were taken at depths of zero to $10 \mathrm{~cm}$, the samples taken from each quadrat were mixed together and placed in black plastic bags, and the samples belonging to each depth were separately transferred to the laboratory. Then, $150 \mathrm{~g}$ of the total soil sample was weighed and separated. This sample was placed in silk bags (Beheshtean et al., 2007) and put in a water container in the laboratory. After several days, the soil was completely washed out and the seeds together with very small stones were left in the silk bags. When the seeds, together with sand grains, were dried, they were counted and identified to the level of the genus by using a binocular stereo-microscope. Seeds that did 
not yield to the pressure applied by forceps were assumed to be healthy (Forcella, 1998). These seeds were counted and the number of seeds per hectare was calculated.

\subsection{Sampling the Floras}

The first sampling was carried out with a quadrat when the corn plants were at the four - leaf stage (June $7^{\text {th }}$ ). Sampling was carried out at the same points where seed bank sampling had been conducted. All the germinated seeds in the quadrat were identified, counted, and then discarded.

Sampling was repeated at the eight- leaf stage (July $4^{\text {th }}$ ) and at tussle formation $\left(\right.$ July $\left.19^{\text {th }}\right)$ in the same way as the first sampling.

Results obtained using the networking method concerning the seed bank and the weed populations were considered as the actual estimate and as the base. Then, in order to compare other methods with the networking method, seed bank and weed seedling sampling were carried out at the mentioned stages using the zigzag, the diagonal, and the random methods. Each method was used 15 times and the mean of the results obtained in each method was considered as the estimate of the mean of the seed bank and weed seedling populations. Next, the following relationship (Colbach et al., 2002) was used to calculate the variance of error in each method:

$$
\mathrm{Z}=\overline{1} / \mathrm{Y} \sqrt{ }(\mathrm{Y}-\mathrm{Y})^{2} / \mathrm{R}
$$

Where $\mathrm{Z}$ is the variance of the error of the method, $\mathrm{Y}$ is the actual mean obtained using the networking method, $\mathrm{Y}$ is the mean of the method employed, and $\mathrm{R}$ is the number of times the sampling was repeated using the method under study. The figures obtained for each method $(Z)$ were compared using the factorial format in the completely randomized design with three replications. The first factor (consisting of three levels) included the three methods of zigzag, diagonal, and random sampling, and the second factor (consisting of three levels) included the dominant weed species in the field (which were the grass species, Amaranthus, and Portulaca).

In order to investigate the relationship between the number of sampling and the changes in the degree of error in estimating weed populations, 5, 10, 15, 20, 25, and 30 samples were taken in each method. Analysis of the variance and comparison of the means were carried out using the method of the least significant difference (LSD) with the help of the SAS software (SAS, 9.1, SAS Institute). The Excel software was used to plot the diagrams.

\section{Conclusions and Discussion}

\subsection{Comparison of Sampling Methods of the Seed Bank}

In estimating the means of the number of seeds, there were no significant differences among the sampling methods regarding any of the species studied (Table 1 ).

Table 1. Analysis of variance of the comparison of the sampling methods in various species observed in the seed bank

\begin{tabular}{lllll}
\hline S.O.V & Degree of Freedom & Mean of Squares & F Value & Pr $>$ F \\
\hline A (Sampling method) & 2 & 0.0000141 & 0.30 & 0.7431 \\
B (Species) & 2 & 0.015975 & 34.04 & $<0.0001$ \\
Ax B & 2 & 0.003464 & 7.38 & 0.0001 \\
Error & 18 & 0.000469 & - & - \\
Coefficient of Variation (\%) & - & 4.33 & - & - \\
\hline
\end{tabular}

The symbols ns, ${ }^{*}, * *$, stand for non-significant and significant at 5 and $1 \%$ level of probability, respectively.

In other words, the variance of error in the estimates of the populations in itself did not show any significant differences among the three sampling methods. However, the variance of error differed in different species (Table 2). 
Table 2. Comparison of the means of variance of the prediction error in the species studied

\begin{tabular}{ll}
\hline Factors & Variances \\
\hline Grasses & 0.13534 \\
Amaranthus & 0.05299 \\
Portulaca & 0.07871 \\
LSD & 0.0215 \\
\hline
\end{tabular}

In general, the estimate of the mean of the population was more accurate for Amaranthus than for the other two species studied.

According to the results of the analysis of variance (Table 1), the sampling methods yielded different results for the different species.

\subsection{Results of the Mutual Effects of the Sampling Method and the Species in the Seed Bank}

As can be seen in Figure 1, in the zigzag method, the least prediction error was that of the species Portulaca oleraceae, and for the other two species (that is, the grasses and Amaranthus retroflexus), the predictions were less accurate but, despite small differences, statistically the same.

In the diagonal method, the least error in predicting the population of the seed bank was that of the grasses and Portulaca oleraceae, and the prediction of the mean of Amaranthus retroflexus in the seed bank was less accurate and less reliable.

In the random method also, the best estimate of the mean (that is, the least variance of error) was that of the grasses with no statistically significant differences between those of the broadleaved species Amaranthus retroflexus and Portulaca oleraceae (Figure 1).

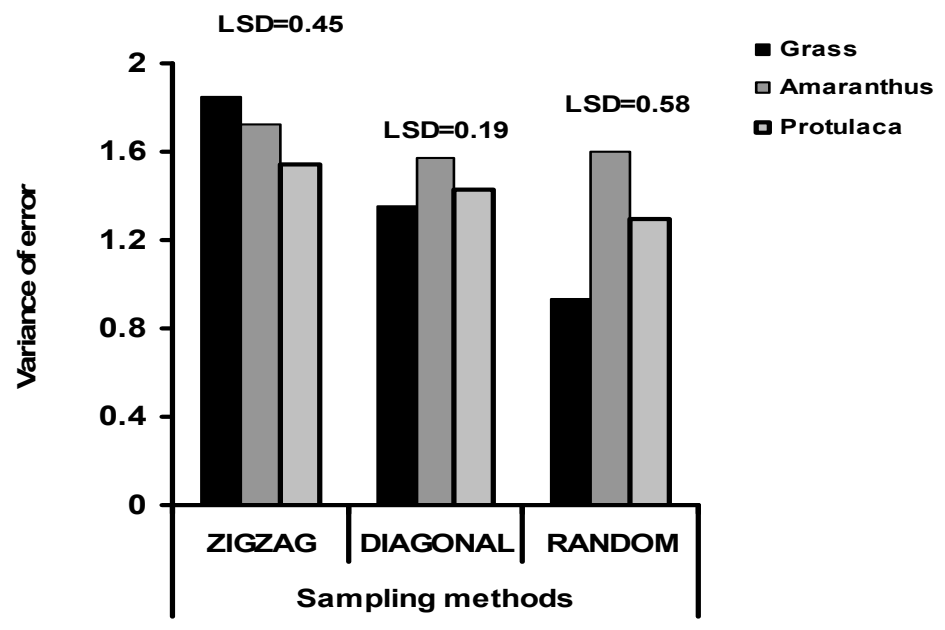

Figure 1. The diagram of the mutual effects of the sampling method and the species in the seed bank

What is obvious is that the differences among the sampling methods and the degree of their accuracy in estimating the populations of the seed bank heavily depended on the species studied. Therefore, where a species like Portulaca oleraceae is the dominant weed in the field, recommending the use of the zigzag method will probably lead to better results. However; if the dominant weed species are the grasses, random sampling can then be more effective and more accurate.

The appearance of Figure 1 suggests that the estimates of the mean population in the seed bank of Amaranthus oleraceae in the three methods were not very different, and that the variance of prediction error of the three methods were very close to each other. 


\subsection{Comparison of Sampling Methods in the Study of Weed Populations in the Field}

In estimating the mean populations of the weeds in the field, not only were the sampling methods and the species studied different but also, as was observed in the seed bank, the degree of the correctness of the results obtained depended on the species (Table 3).

Table 3. Analysis of variance of the factors of sampling methods and the species in the floras

\begin{tabular}{lllll}
\hline S.O.V & Degree of Freedom & Mean of Squares & F Value & Pr $>$ F \\
\hline A (Sampling method) & 2 & 0.10231795 & 20.17 & $<0.0001$ \\
B (Species) & 2 & 0.51535799 & 101.58 & $<0.0001$ \\
Ax B & 2 & 0.04299228 & 8.47 & 0.0005 \\
Error & 18 & 0.09131894 & - & - \\
Coefficient of Variation (\%) & - & 5.086182 & - & -
\end{tabular}

The symbols ns, *, **, stand for non-significant and significant at 5 and $1 \%$ level of probability, respectively

The random sampling method yielded more accurate means for all the species studied, and the species were also different in this respect: the least degree of error was that of the grasses, with Portulaca and Amaranthus coming second and third, respectively; but, what is more important, is the dependence of the correctness of the methods on the species.

In all three methods, the best estimate of the mean of the population was that of the Amaranthus species, and the variance of error of this species was less than those of the other two (Table 4).

Table 4. Comparison of the means of the factors related to all the floras

\begin{tabular}{ll}
\hline Factors & Variances \\
\hline Zigzag & 1.47649 \\
Diagonal & 1.44618 \\
Random & 1.27853 \\
LSD & 0.0705 \\
Grasses & 1.15230 \\
Amaranthus & 1.62979 \\
Portulaca & 1.41911 \\
LSD & 0.0705 \\
\hline
\end{tabular}

Therefore, we can conclude that all three methods performed better, and were more accurate, for the Amaranthus species, and that there was the same trend in the order of differences between the random and the diagonal methods: Portulaca came after Amaranthus with respect to the accuracy of the mean of the population, while the estimate for the mean of the population of the grasses exhibited the greatest degree of error. In all, the general conclusion that can be drawn from the flora diagram is that the random and the diagonal methods are relatively more correct for broadleaved species, while the zigzag method is the best in estimating the mean of the population of the grasses.

These results are in agreement with those obtained by Forcella and Colbach who stated, in their studies in 1999, that the zigzag method is more accurate for grass species. 


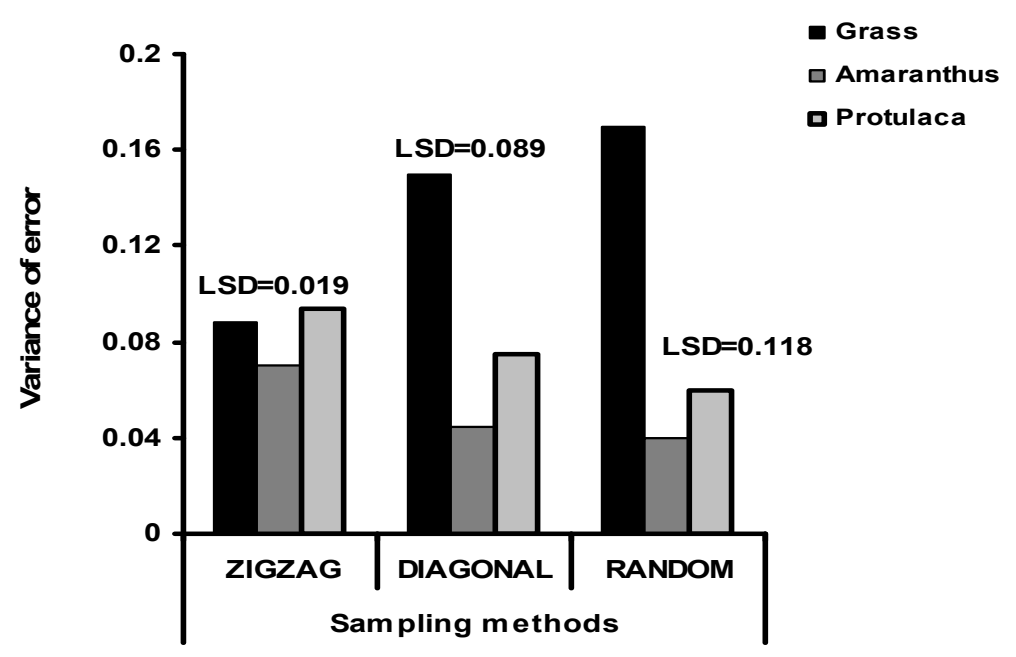

Figure 2. The diagram of the effects of the sampling method and the species in the seed bank

The relationship between the number of samples with the correctness of the results of the predictions on the means of the seed bank and with the populations of the weeds:

1). The relationship of the number of samples with the different methods in the seed bank

Obviously, the more the number of samples taken in each method of estimating the population of the weeds, the more information will be gathered and, certainly, the more correct the predictions will be. However, taking a large number of samples requires spending a lot of time and money; therefore, it will be very useful to scientifically find a reasonable number for the samples taken that will be reliable, regarding the predictions made and the accuracy of the results obtained, and also acceptable, with respect to the time and the money that have to be spent.

The changes in the variance of error in predicting the mean of the population, as was expected, showed a declining trend when the number of samples increased (Figures 3, 4, and 5). That is, with an increase in the number of samples, the degree of error decreased; but when the number of samples exceeded 15, this trend became almost constant: increasing the number of samples to 25 and 30 did not cause much difference in the accuracy of the prediction, nor did it bring about further reduction in the variance of error.

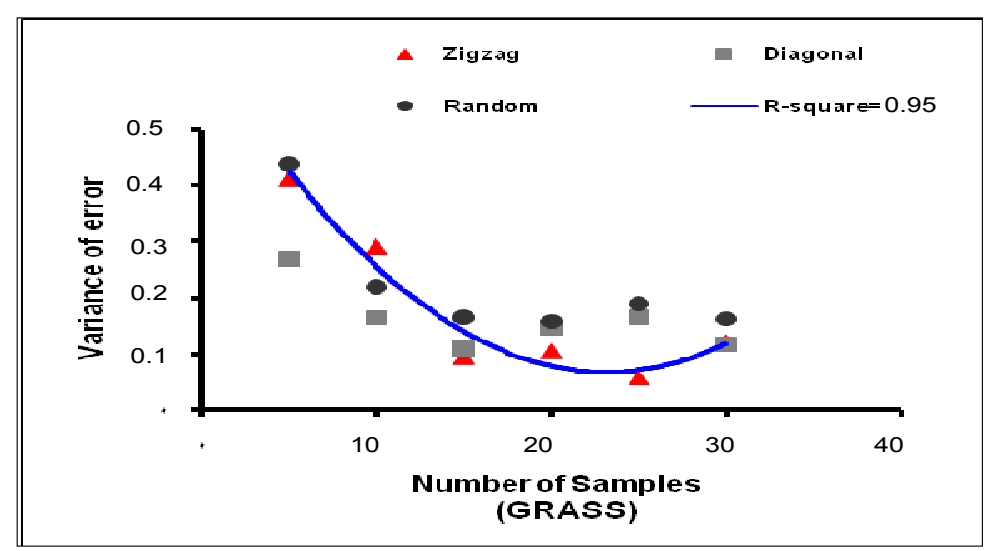

Figure 3. The relationship of variance and the number of samples of grasses in the seed bank 


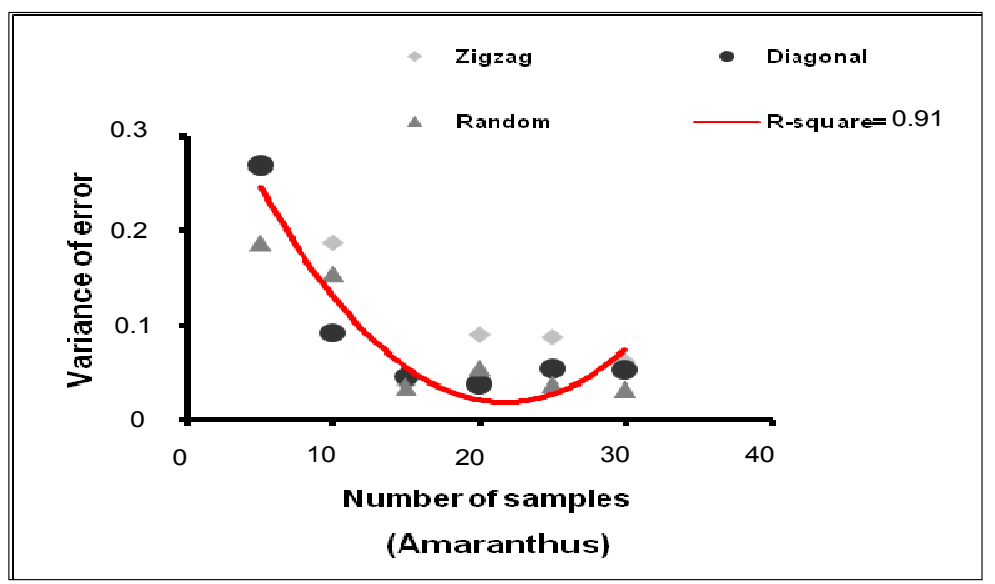

Figure 4. The relationship of variance and the different number of samples in the Amaranthus species in the seed bank

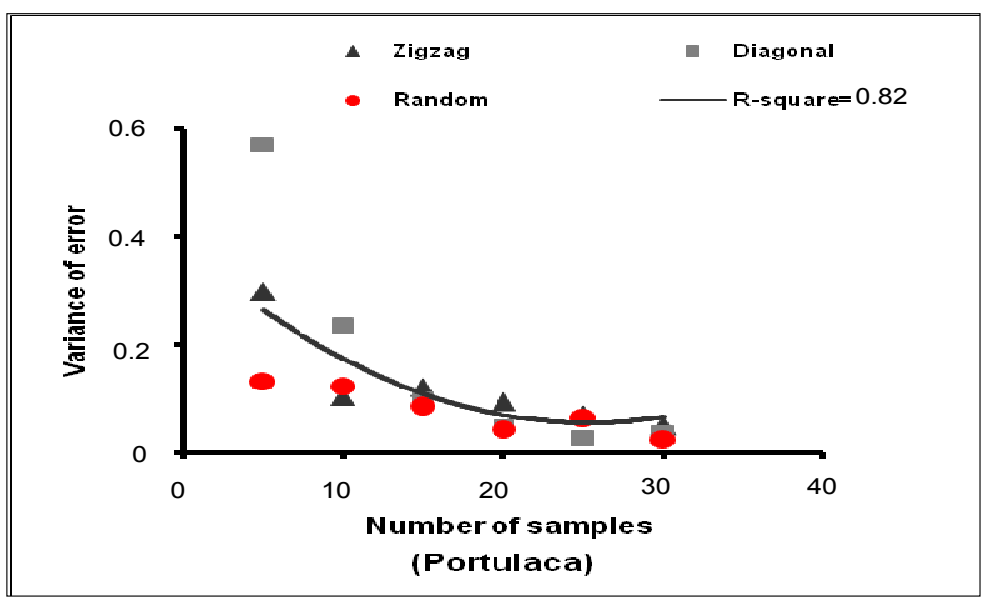

Figure 5. The relationship of variance and the number of samples in the Portulaca species in the seed bank

This trend was almost similarly repeated for all the three species of grasses, Amaranthus, and Portulaca (Figures 6, 7, and 8). Results obtained by Colbach et al. (1998) confirm the above finding.

Therefore, results obtained from 15 samples are probably both accurate enough and economically practical; and it is recommended that 15 samples be taken for the seed bank and for estimating the mean of the populations of the weeds in a field similar in size to the field in our study.

2). The relationship between the number of samples and the sampling methods of weed populations

The results obtained, and the trend observed, in the seed bank was not repeated in weed populations. In fact, by increasing the number of samples from 5 to $10,15,20,25$, and 30, no special trend was observed in the degree of error; and as for the populations of the weeds during the growing season, for all three species, results obtained from 5 samples were almost the same as those from 30 samples. It may be possible to achieve a descending and declining trend by increasing the number of samples, but results of our study suggest that what is achieved from 5 samples is probably reliable to a large extent , and at the same time very desirable as far as the required time and money are concerned (Figures 6- 8). 


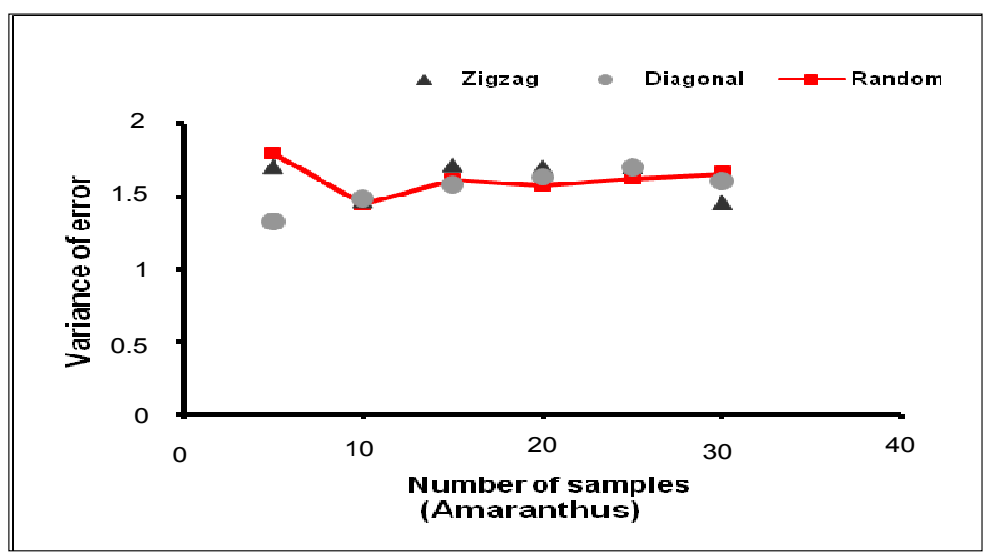

Figure 6. the relationship between variance and different number of samples of the grasses in the floras

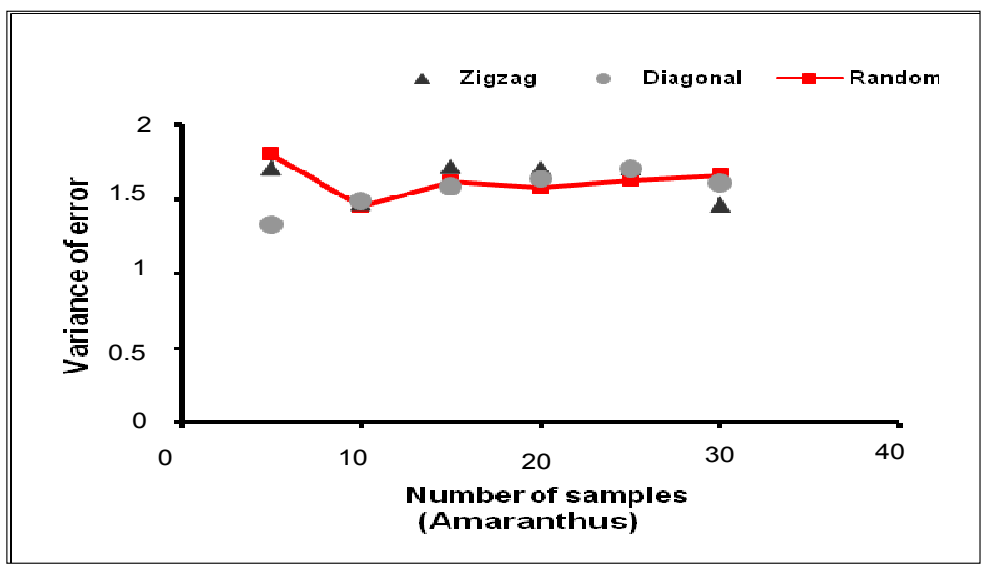

Figure 7. The relationship between variance and different number of samples of the genus Amaranthus in the floras

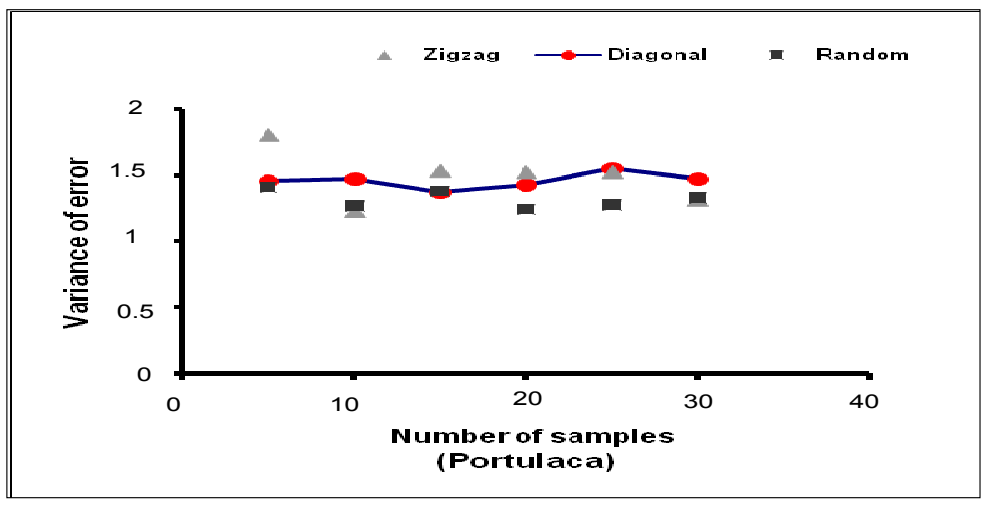

Figure 8. The relationship between variance and the different number of samples of the species Portulaca in the floras

Results obtained by Forcella and Colbach (1999) also confirm this finding. They stated in their reports that the systematic method is more accurate than other methods because it covers more of the field studied, but added that with an increase in the size of the field the accuracy of the systematic method decreases. They also said that if a 
small number of samples is to be taken, it will be better to use the random method because its performance is independent of the species studied.

\section{References}

Auld, B. A., and Tisdell, C, A. (1987). Economic threshold and response to uncertainty in Weed control. Agricultural Systems, 25, 219-227.

Ball, D. A. (1992). Weed seed bank response to tillage, herbicide and crop rotation sequence. Weed Science, 40, 654-656.

Beheshtean, M., Mesgaran, M. B., Rahimian, H., Zand, E., \& Alizadeh, H. (2007). Comparison of three methodologies for efficient seed extraction in studies of soil weed seedbank. Weed Res., 47, 472-478.

Brain, P., \& Cousens, R. (1990). The effect of weed distribution on prediction of yield Loss. Journal of Applied Ecology, 27, 735-742.

Cardina, J., Johnson, G. A., \& Sparrow, D. H. (1997). The nature and consequence of weed spatial distribution Weed Science, 45, 364-373.

Colbach, N., \& Debaeke, P. (1998). Integrating crop management and crop rotation effects into models of weed population dynamics: A Review. Weed Science, 46, 717-728.

Colbach, N., Forcella, F., \& Johnson, G. (2002). Temporal trends in spatial variability of weed populations in continuous no-till soybean. Weed Science, 48, 366-377.

Conn, J. S., Proctor, C. H., \& Skroch, W. A. (1982). Selection of sampling methods determine weed Abundance in apple (Malus domestica) orchards. Weed Science, 30, 35-40.

Dent, J. B., Fawcett, R. H., \& Thornton, P. K. (1989). Economics of crop protection in Europe with reference to weed control. In Proceedings 1989 Brighton Crop Protection Conference- Weeds. Brighton, UK, 917-926.

Forcella, F., \& Colbach, N. (1999). Application of weed seed bank ecology to weed management. USDA, Agricultural Research Service, 23-35.

Forcella, F., Durgan, R., \& Buhler, D. D. (1996). Management of weed seedbank ecology to Low-input. International Weed Control Congress. International Weed Science Society Copenhagen, 107.

Gold, H. J., Bay, J., \& Wilkerson, G. G. (1996). Scouting for weeds, negative binomial distribution Weed Science, 44, 504-510.

Johnson, G. A., Mortensen, D. A., \& Gotway, C. A. (1996). Spatial and temporal analysis of weed seedling populations using geostatistics. Weed Science, 44, 704-710.

Legendre, P., \& Fortin, M. J. (1989). Spatial pattern and ecological analysis. Vegetatio, 80, 107-138.

Marshall, E. J. P. (1988). Field-scale estimates of grass weed population in arable land. Weed Research, 28 , 191-198.

Thornton, P. K., Fawcett, R. H., Dent, J. B., \& Perkins, T. J. (1990). Spatial weed distribution and economic thresholds for weed control. Crop Protection, 9, 337-342.

Wallinga, J., Grasman, J., Groeneveld, R. M., Kropff, M. J., \& Lotz, L. A. P. (1999). Prediction of weed density: the increase of error with prediction interval, and the use of long-term prediction for weed management. Journal of Applied Ecology, 36, 307-316.

Wiles, L. J., Oliver, G. W., York, A. C., Gold, H. J., \& Wilkerson, G. G. (1992). Spatial distribution of broadleaf weeds in North Carolina soybean (Glycine max) fields. Weed Science, 40, 554-557.

Zadoks, J. C. (1985). On the conceptual basis of crop loss assessment: the threshold theory. Annual Review of Phytopathology, 23, 455-473. 